Wbrk Funct i on Measurement of Er-oxi de/W 100) Surface by using of Phot oemi ssi on El ectron M cr oscope

\begin{tabular}{|c|c|}
\hline 著者 & NAKANE Hi deaki, KAWAKUBO Takashi \\
\hline $\begin{array}{l}\text { j our nal or } \\
\text { publ i cat i on titl e }\end{array}$ & $\begin{array}{l}2015 \text { 28t h I nt er nat i onal Vacuum Nanoel ect r oni cs } \\
\text { Conf er ence ( I VNC) }\end{array}$ \\
\hline page $r$ ange & $110-111$ \\
\hline year & 2015 \\
\hline URL & ht t p: //hdl . handl e. net /10258/00009008 \\
\hline
\end{tabular}




\section{Work Function Measurement of Er-oxide/W(100) Surface by using of Photoemission Electron Microscope}

\author{
Hideaki Nakane \\ Department of Information and Electronic Engineering, \\ Muroran Institute of Technology, \\ Muroran, Japan \\ nakane@mmm.muroran-it.ac.jp
}

\author{
Takashi Kawakubo \\ Department of Communications Network Engineering, \\ Kagawa National College of Technology, \\ Kagawa, Japan
}

\begin{abstract}
A cathode material of a low work function is needed to achieve a high performance electron source. We measured the work function of $W(100)$ surface modified with $\mathrm{Er}_{2} \mathrm{O}_{3}$ by using of photoemission electron microscope. The work function of Eroxide/W(100) surface is measured to be $2.65 \mathrm{eV}$.
\end{abstract}

Keywords- Erbium oxide; W(100) surface; PEEM; work function.

\section{INTRODUCTION}

The $\mathrm{ZrO} / \mathrm{W}(100)$ thermal-field emission cathode is used for electron beam systems of high brightness as an electron microscope. The work function of $\mathrm{ZrO} / \mathrm{W}(100)$ thermal-field emission cathode has been reported to be 2.7 2.9eV [1]. A work function of a cathode is generally estimated by FowlerNordheim plot (F-N plot). However, there are some ambiguities in this method. The work function measured by using of photoemission electron microscope (PEEM) is more direct physical constant. And the sample surface can be observed. These advantages on measurements make a search of low work function materials easier. To obtain the lower work function cathode material, it is needed to measure the work function of W(100) surface modified with other metaloxid [2][3][4][5][6]. We measured the work function of $\mathrm{W}(100)$ surface modified with $\mathrm{Er}_{2} \mathrm{O}_{3}$ by using of PEEM.

\section{EXPERIMENTAL PROCEDURES}

The work function of W(100) surface modified with $\mathrm{Er}_{2} \mathrm{O}_{3}$ was measured by using of photoemission electron microscope(PEEM). The theory of measurement by PEEM derived from photoelectric effect. Therefore, it is true at only absolute zero. To calculate a work function from PEEM image at the room temperature, Fowler plot is used (figure 1). The followings are the Fowler's equation which denotes photoelectron emission current density;

$$
\begin{aligned}
& J_{p}=\frac{4 \pi e m k^{2}}{h^{3}} T^{2} f(\alpha)=A T^{2} f(\alpha) \\
& \alpha=\frac{h\left(f_{0}-f\right)}{k T}
\end{aligned}
$$

where $\alpha$ is an experimental parameter. Where $f_{0}$ is threshold optical frequency for photoelectron emission and is a characteristic parameter for the material examined. The work function can be deduced from this threshold frequency $f_{0}$. And $f$ is the optical frequency of the irradiated light and $T$ is the sample temperature.

The Fowler's equation can be modified by

$$
\ln \left(\frac{J_{p}}{T^{2}}\right)=\ln A+\ln f(\alpha)
$$

where $A$ is the Richardson constant. The deduced values of $\ln \left(J_{p} / T^{2}\right)$ are plotted as a function of the parameter $\alpha$ as shown in figure 1. In figure 1, the upper curve is theoretical curve and the lower one corresponds to experimental values. A work function can be estimated from horizontal shift between two curves.

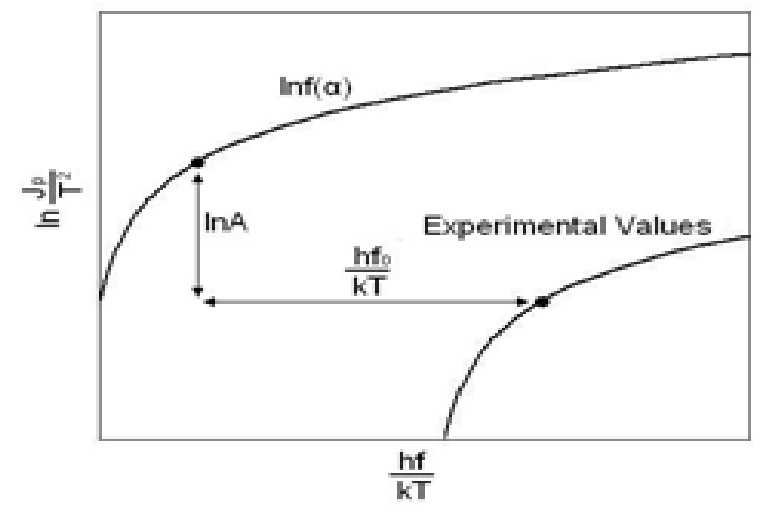

Fig. 1. Fowler plot 
The sample used in this experiment is a circular single crystal tungsten plate of $8 \mathrm{~mm}$ in diameter and $0.1 \mathrm{~mm}$ in thickness. A small amount of $\mathrm{Er}_{2} \mathrm{O}_{3}$ powder was dissolved in ethanol, and it is put on the sample surface. The sample is fixed on the specimen stage in PEEM chamber of $10^{-8} \mathrm{~Pa}$ (figure 2).

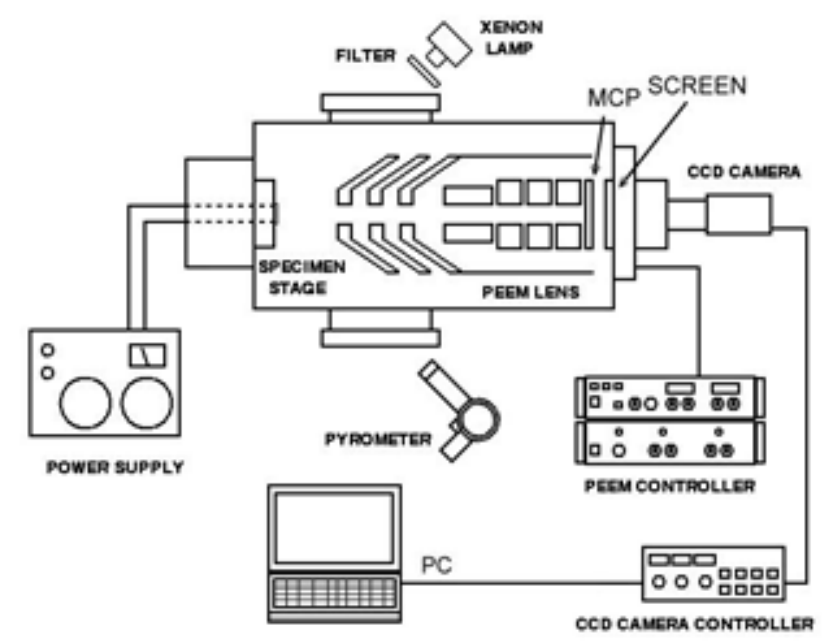

Fig. 2 Experimental apparatus for taking PEEM images

The sample was heated at $1400 \mathrm{~K}$ by electron bombardment and the low work function surface was realized on the planar surface. To obtain the work function, PEEM images when the sample is irradiated with the light of specific frequency is needed. The each PEEM images that the sample is irradiated with the light of wavelength from 300nm to $460 \mathrm{~nm}$ every 20nm are taken. The PEEM images of W(100) surface modified with $\mathrm{Er}_{2} \mathrm{O}_{3}$ are shown in figure 3.

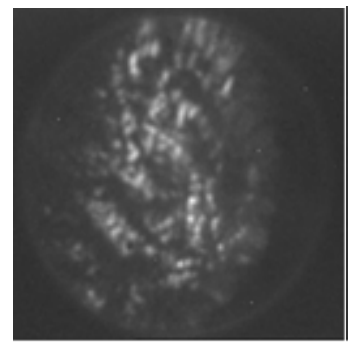

$300[\mathrm{~nm}]$

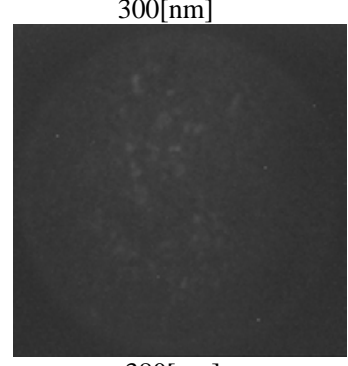

$380[\mathrm{~nm}]$

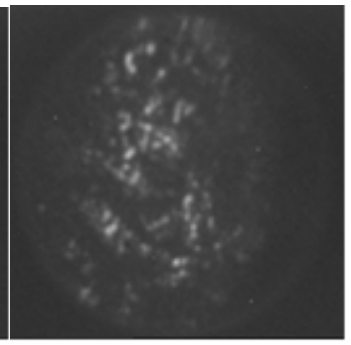

$340[\mathrm{~nm}]$
Fig. 3 PEEM images of Er-oxide/W(100) surface with every wavelength.

In this study, the work function was estimated with the Fowler plot for the emission current density. However, the PEEM system cannot measure directly the emission current. Thus, we estimated the emission current density from the local brightness of the photoelectron image.

\section{RESULTS}

The work function of Er-oxide/W(100) is measured in optical method by using PEEM. Fowler plot is used for estimating the work function of room temperature from PEEM data. The Fowler plot for the result of Er-oxide/W(100) is shown in figure 4. This Fowler plot shows that the horizontal shift is 100.7. The result is affected by Schottky effect because of applied lens voltage of PEEM. The influence of Schottky effect is calculated $0.06 \mathrm{eV}$ when considering that the voltage is $7.5 \mathrm{kV}$, and the distance between the sample and the PEEM electrode is $3 \mathrm{~mm}$. The estimated work function of $\mathrm{W}(100)$ single crystalline surface modified with $\mathrm{Er}_{2} \mathrm{O}_{3}$ is $2.65 \mathrm{eV}$. The work function of the $\mathrm{W}(100)$ surface is decreased from $4.6 \mathrm{eV}$ by modifying with $\mathrm{Er}_{2} \mathrm{O}_{3}$. In the PEEM images, it can be confirmed that $\mathrm{Er}_{2} \mathrm{O}_{3}$ is diffused on the W(100) surface enough. And Er-oxide/W(100) is keeping the stable low work function surface even if it is heated repeatedly. Therefore Eroxide/W(100) can be expected to use as a thermal-field emitter.

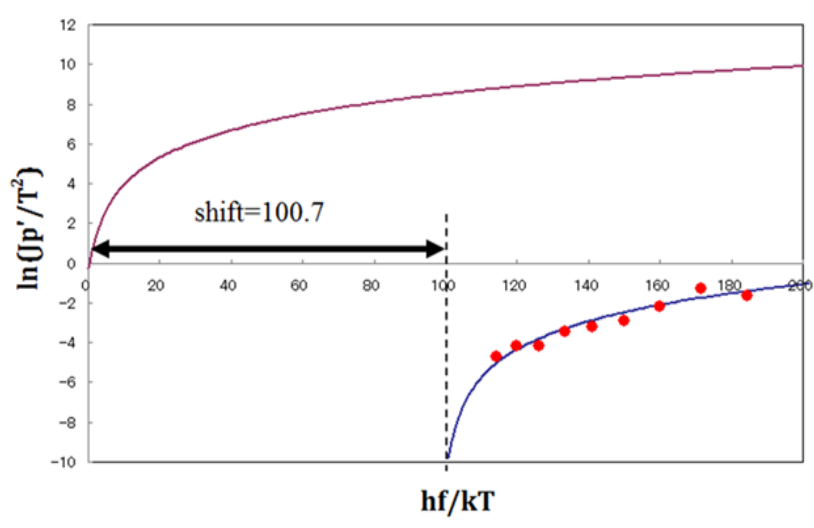

Fig. 4 Fowler plot for the result of Er-oxide/W(100)

\section{REFERENCES}

[1] Advances in Electronics and Electron physics Part 3, ACADEMIC PRESS, NEW YORK, N. Y. 1956, p.91

[2] T. Kawakubo, Y. Saito, N. Miyamoto, H. Nakane, and H. Adachi, J. Vac. Sci. Technol. B22(3), p.1258, (2004)

[3] Y. Saito, T. Yada, T. Kawakubo, K. Minami, H. Nakane, H. Adachi, J. Vac. Sci. Technol. B22(6), p.2743, (2004)

[4] T. Kawakubo, Y. Simoyama, H. Nakane, H. Adachi, J. Vac. Sci. Technol. B26(3), p.1395, (2008)

[5] T. Kawakubo, Y. Nakano, H. Nakane, J. Vac. Sci. Technol. B27(3), p. 698 (2009)

[6] H. Nakane, Y. Nakano, T. Kawakubo, J. Vac. Sci. Technol. B27(3), p. 719 (2009) 